\title{
6. Dispositivos de creación: experiencia de formación en investigación creación ${ }^{1}$
}

DOI: https://doi.org/10.38017/9789588966458.06

Etna Castaño Giraldo²

Cuando llegó del decano de la Facultad de Ciencias de la Educación, Humanidades y Artes de la Fundación Universitaria Juan de Castellanos, el profesor Édgar Giovanni Rodríguez, la invitación a participar en la escritura de este libro, instantáneamente vinieron a mí algunos temas que considero podrían tener una relativa importancia para ser profundizados, y de este modo intentar enriquecer la discusión en relación a la filosofía del francés Gilles Deleuze. Como docente investigadora y artista, uno de mis propósitos es lograr que los estudiantes pongan en uso determinados conceptos, y fue entonces cuando pensé que quizás esta sería la oportunidad para compartir una experiencia de formación en investigación creación que buscó poner en uso el concepto de dispositivo deleuziano como una herramienta para el diseño metodológico en los procesos de investigación creación de los estudiantes de IV semestre del programa de Artes Visuales de la Universidad de Nariño, a quienes quiero agradecer por su compromiso con esta iniciativa.

1 Quiero expresar mi amor incondicional e infinito a mi compañero de vida Jaime Andrés Meza Saldaña por hacer de nuestro hogar y nuestra vida el espacio perfecto para que la creación artística y la escritura pervivan haciendo inconmensurable nuestras existencias. Sin él estas líneas no se habrían escrito. Además, quiero agradecer a mi hermano James Delgado Giraldo por sus aportes a la discusión y su compromiso con el pensamiento del presente.

2 Docente de tiempo completo adscrita al Departamento de Artes Visuales de la Universidad de Nariño. Docente de Investigación en las especializaciones en Lúdica Educativa y Atención e Intervención a la Primera Infancia de la Fundación Universitaria Juan de Castellanos. Magíster en Educación de la Universidad Pedagógica Nacional. Maestra en Artes Plásticas de la Universidad de Caldas. fractal16@yahoo.es 
Algo en lo que trabajamos permanentemente en el seminario de Arte e Investigación, es que la investigación es una práctica y, por esa razón, no puede ser transmitida, sino que ella debe ser lograda a partir de la experiencia individual y/o colectiva. Ahora bien, ¿cómo reconstruir la experiencia y cómo hacerlo a partir del relato escrito para efectos de lo que este libro buscaba? Solo empezaré desde el principio, es decir desde la ocurrencia que a todos llega cuando una experiencia inicia o, por el contrario, cuando ella concluye, pero aún más iremos a su fuente, su origen. La escritura será, para algunos, anterior, en tanto se plantea como un ejercer proyectivo; para otros, ocurrirá después, al modo de una reconfiguración en el presente. En este caso, transcurriremos en ambas direcciones, lo anterior y lo presente, el antes y el ahora, como lo plantea Walter Benjamin.

De este modo, intentaré reconstruir la experiencia de un experimento artístico, investigativo y especialmente pedagógico desarrollado con mis estudiantes, en el que, haciendo uso de la pregunta planteada por Deleuze: ¿qué es un dispositivo? publicada en el libro Michel Foucault Filósofo (1990), Deleuze responde a la pregunta que él mismo se plantea. En un esfuerzo por descifrar el sentido de los dispositivos, con los que se asocian los estudios de Michel Foucaul, Deleuze plantea que los dispositivos son una suerte de "conjuntos multilineales" (Tejidos), en donde cada uno de sus componentes (líneas) (hilos) toma su propia dirección creando procesos de desequilibrio en los que, en ocasiones, las líneas se acercan y en otras se distancian. Aquella definición nos dejó perplejos, porque nos dejaba completa libertad a la imaginación cuando al intentar visualizarla (verla en imágenes) pretendíamos. Continúa Deleuze (1990):

Cada línea está quebrada y sometida a variaciones de dirección (bifurcada, ahorquillada), sometida a derivaciones. Los objetos visibles, las enunciaciones formulables, las fuerzas en ejercicio, los sujetos en posición son vectores o tensores... Es siempre en una crisis cuando Foucault descubre una nueva dimensión, una nueva línea. Los grandes pensadores son algún tanto sísmicos; no evolucionan, sino que avanzan por crisis, por sacudidas (p. 155). 
Fue esta última aproximación la que nos embarcó definitivamente en esta travesía. Nos propusimos ir en una trayectoria investigativa y de creación, en la que los dispositivos no estuviesen establecidos, sino que se dibujaran en su natural ocurrir como ya lo leímos en la definición de Deleuze. El dispositivo dejó de entenderse como un sistema previo de regulaciones intrínsecas a la complejidad humana relacionadas con el poder y el gobierno. Más bien, pretendíamos comprender cómo es que las decisiones en la investigación creación o como preferimos nombrarla, investigación basada en la creación, van dejando una huella en el espacio invisible y visible en el que la experiencia se configura como acontecimiento, tal como ocurre con los dispositivos que describe Deleuze, y además la pulsión que empuja esta búsqueda está íntimamente ligada con la crisis, al menos para el artista creador. Así fue que comenzamos. La "decisión" en este texto se comprende como un concepto clave, porque depende de ¿quién decide? Y es precisamente ese quién el que debe desequilibrarse, entrar en crisis, sacudirse.

\subsection{Remover las líneas de sedimentación}

Creamos un espacio de debate para analizar, en primer lugar, las complejidades de los procesos creativos como actos de reflexión que instaban a cada uno a iniciar un ejercicio investigativo signado por la experimentación, en la que al comienzo todo era incertidumbre, esto también nos obligó a hablar de un "sujeto incierto"; es decir, un sujeto sin verdades, un sujeto puro, sin objeto, en crisis, que para seguir adelante inevitablemente debería aprender del arte de armonizar las energías sutiles. Los estudiantes no distinguían el camino y menos el lugar al que nos aproximábamos; yo, por el contrario, lo conocía, pero de él solo podía decir que cada vez se presentaba de formas muy distintas. De este modo, solo debíamos dejarnos afectar por lo que el mundo nos presenta, puesto que no todo parecía afectarnos. Aquí, se planteó no solo la atención sobre lo que nos afecta, sino por aquel que es afectado, sin historia, su presencia; en últimas, su práctica de ser. Visualizar y demarcar estas atenciones en un transitar eran propósitos ineludibles. 
Ese dibujo sin referente ni modelo dejaría apreciar cada dispositivo, es decir cada línea de subjetivación, objetivación, fuga, tensión, poder, saber, deseo, miedo y escape; entre otros, que delimitaban el ser y los objetos de investigación, sus abordajes epistemológicos y de creación, hablando acerca del sujeto creador y sus avatares. No se trataba de replicar al pie de la letra lo que el dispositivo implicaba, sino de aprovecharlo para comprender las fuerzas que impulsan la búsqueda creativa a partir de la investigación, que es entendida como una fuerza permanente y en crisis. La intención era identificar las posibilidades de los dispositivos, en su modalidad más intrincada al modo de un tejido para despejar, paradójicamente, la ruta de la investigación basada en la creación que mis estudiantes transitaban. Estas ideas se fueron esclareciendo en la medida en la que, en cada discusión, los pensamientos se activaban haciendo de la investigación una práctica en el sentido en el que Hannah Arendt la comprende; es decir, como una acción-ética, para nosotros comprometida con el territorio. Con ella no solo intervenimos el mundo, sino que radicalmente hacemos mundo.

En las prácticas artísticas contemporáneas, el término de investigación establece un código compartido que no encaja con un solo modelo, sino que implica un espacio dinámico en el que intervienen diferentes motivaciones, y es por ello por lo que el pretexto del dispositivo permitió alterar las preconcepciones que, sobre la investigación basada en la creación, tenían los estudiantes condiciéndonos poco a poco hacia el concepto del tejido. Alterar, esta era la disposición general, significaba remover un sinnúmero de ideas solidificadas en la mente y las sensaciones de los estudiantes que experimentaban hasta ahora un contacto con la investigación como posibilidad para adentrarse aún más en la creación artística y no solo eso, sino como camino para relacionarse consigo mismo y los otros. Este espacio dinámico en el que intervienen diferentes metodologías, conocidas Metodologías Compartidas en Procesos Artísticos, abren una perspectiva hacia proyectos que se nutren de otras disciplinas para crear sus propios métodos o que incluyen la experimentación como proceso de investigación. 
Desde el seminario de Arte e Investigación, pensamos la investigación basada en la creación como un modo particular de conocimiento, siendo la creación artística el producto. En él encontramos como condición particular la expresión de una serie de confrontaciones teóricas y técnicas que el artista hace con y de su experiencia en el mundo, sin que se pierda de vista su condición y dimensión social y desde el territorio, lo que nos exigía abrirnos a analizarla desde su propia complejidad, y fue en esa apertura donde, además de lo ya mencionado, encontramos una oportunidad en el dispositivo tal y como lo describe Deleuze.

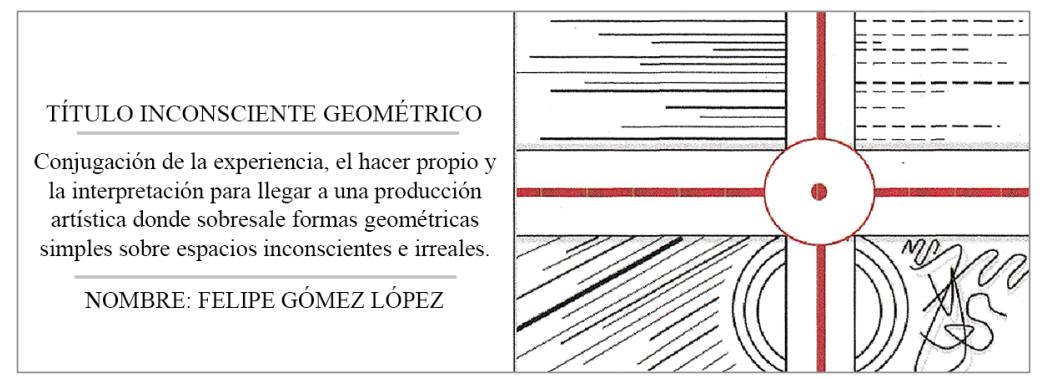

Dispositivo 1. Felipe Gómez. Estudiante V semestre. Artes Visuales.

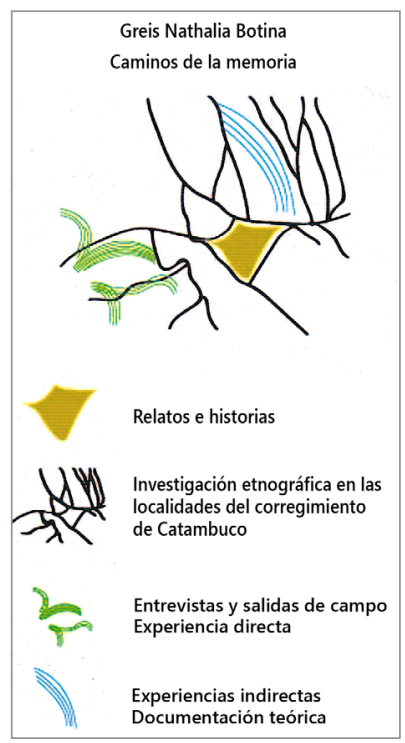

Dispositivo 2. Greis Botina. Estudiante

VI semestre. Artes Visuales. 


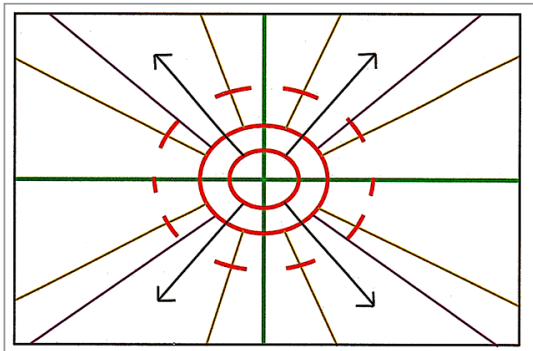

Tomaré como estudio a los árboles como una población invadida por el hombre donde su materia es utilizada para el "desarrollo" del ser humano, sin embargo el árbol también es un símbolo de inspiración y conexión espiritual para algunas personas
NOMBRE: OSCAR DANIEL CUASTUMAL PATIÑO

TÍTULO: MA-TALAS

PARA LLEGAR A UNA RELEXIÓN EL SER HUMANO INVESTIGA, ANALIZA, CREA. Y MEDIANTE EL ARTE ES POSIBLE RESOLVER EL PROBLEMA

VIVIMOS RODEADOS DE SERES QUE TIENEN MÁS QUE UNA SIMPLE MATERIA, ES SENTIR LA CONEXIÓN PARA REFLEXIONAR Y PENSAR SOBRE LO QUE ESTAMOS HACIENDO CON ELLOS

"CUANDO LOS ÁRBOLES SE VAN, LA VIDA SE VA CON ELLOS"

- GANESH PRASAD ACHARYA KAUSHIK KATTY RAY

Dispositivo 3. Oscar Cuastumal. Estudiante V semestre. Artes Visuales.

Como se observa, en este primer ejercicio de construcción individual de un dispositivo de creación pensado como herramienta para el diseño metodológico en investigación creación, los estudiantes aún mantienen una fuerte relación con el texto y la narrativa del dispositivo descrito por el filósofo francés. Se observa en estas visualizaciones una preocupación por determinar "conjuntos multilineales" (tejidos), definidos por características un tanto similares a las que explicita Deleuze en su texto. Sin embargo, en algunos casos los estudiantes intentan tímidamente salir, escapar de las pretensiones discursivas filosóficas y adentrarse en sus propias búsquedas comprensivas e interpretativas de la realidad y de su propio ser, aprovechando la versatilidad del concepto mismo de dispositivo, y este hallazgo reitera una vez más nuestra intención inicial, incluso en algunos casos, es posible identificar el esbozo de una planimetría del territorio, que refleja la capacidad del dispositivo de no solo evidenciar la huella del trayecto investigativo, sino que al tiempo permite trazar los límites y umbrales del propio objeto de estudio y su creador, lo que constituye una forma de visualización de la abstracción en el caso de un creador en artes dejando al descubierto la trama y la urdimbre que le componen. Es decir que, los dispositivos se constituyeron en una presencia de la subjetividad del artista, en la que la producción de ella se daba a través de un proceso del que no escapan los objetos, en tanto ambos, sujeto y objeto, hacían parte del mismo proceso, al que se sumaba la relación con el territorio o el espacio de "habitancia". 
Esta forma de entender la investigación basada en la creación como una práctica, se encuentra atravesada por múltiples condiciones, como se observa en el caso de los dispositivos 1, 2 y 3 (ver imágenes), en los que se esbozan algunos temas de interés que condicionan la construcción del dispositivo forzando en cierto sentido su visualización y, al mismo tiempo, este condicionamiento determinará las maneras en las que la subjetividad-objetividad se construyen y se abordan.

\subsection{Fugarse}

Ya desde el primer ejercicio del diseño metodológico basado en el concepto de dispositivo, fue posible observar cuáles son las preguntas que a cada estudiante se le presentan como parte de su habitar la experiencia sensible de encontrarse en un mundo que lo convoca y lo llama, para el que es necesario afinar todos los sentidos, y no solo aquellos del cuerpo como habitáculo de la conciencia, sino de la mente; ambos, cuerpo y mente, producen un proceso de entendimiento que, al ser dibujados por las posibilidades que el dispositivo ofrece, revelan para el sí mismo del creador las respuestas a algunas de las preguntas que le invitan y le confrontan. Es así como se distinguieron las condiciones que afectan y estimulan los procesos de creación, y esto pareció apaciguar momentáneamente el desborde frenético e incontrolable que, en ocasiones, bloquea el acto creativo para pasar a comprenderlo y relacionarse con él, sin perder su fuerza, de un modo más consciente y consecuente, o al menos así ocurrió para mis estudiantes. Ello los condujo a no abandonar tan fácilmente sus intereses, como suele ocurrir, en cambio su ansiedad de creación fue armonizada y, en ese sentido, se logró mayor continuidad y disciplina en la búsqueda, proporcionando una oportunidad a nuevas líneas de fuga. 


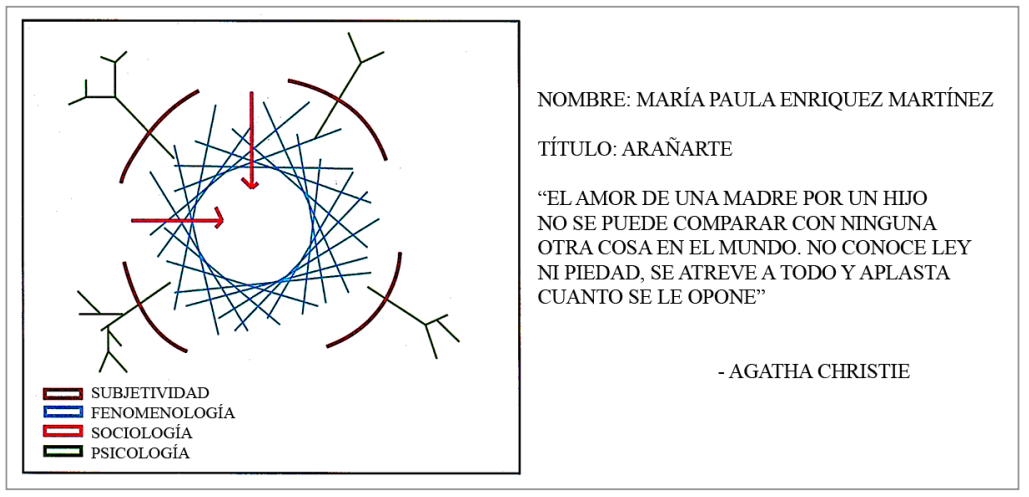

Dispositivo 4. María Paula Enríquez. Estudiante V semestre. Artes Visuales.

\begin{tabular}{|l|l|}
\hline Identidad Cultural \\
$\begin{array}{c}\text { Presentado por: } \\
\text { Esteban Taimal } \\
\text { Universidad de Nariño } \\
\text { Arte e Investigación } \\
2019\end{array}$
\end{tabular}

Dispositivo 5. Esteban Taimal. Estudiante V semestre. Artes Visuales.

Los dispositivos 4 y 5 (ver imágenes) nos trasfieren ya a otro nivel de la experiencia, aquí vemos reflejados lo que llamaría Deleuze las líneas de fuga. En estos dispositivos, los estudiantes comienzan un proceso de asociación distinto, en la medida en que liberan y expulsan una fuerza vital contenida en cada uno de ellos, expresando sentimientos, sensaciones, emociones y pensamientos más concretos y que son visibles en las expresiones gráficas del dispositivo. Incluyen otro tipo de tejidos, siempre inspirados en el inicial, pero agregando, aunque con alguna timidez, imágenes otras que contribuyen a su ejercicio de diseño metodológico. Pienso que 
es oportuno aclarar que cada dispositivo creado por los estudiantes, debía reflejar una reflexión propia con relación a cómo cada sujeto de creación elaboraba su ruta o desplazamiento en el proceso de investigación creación. Mientras el dispositivo se configuraba, la práctica artística surgía de modo simultáneo; por lo que ambos, dispositivo y proceso de creación, marchaban al unísono, aunque no siempre acertábamos. Para muchos fue difícil el comienzo, no lograban compenetrarse con la intención de este experimento y hasta el final quedaron insatisfechos con los resultados, asegurando que no era necesaria la investigación en los procesos de creación. Pese a no encontrarnos de acuerdo con ellos, siempre se respetaron las opiniones y se buscó validar cada opinión con argumentos.

\subsection{Las fracturas/Los quiebres}

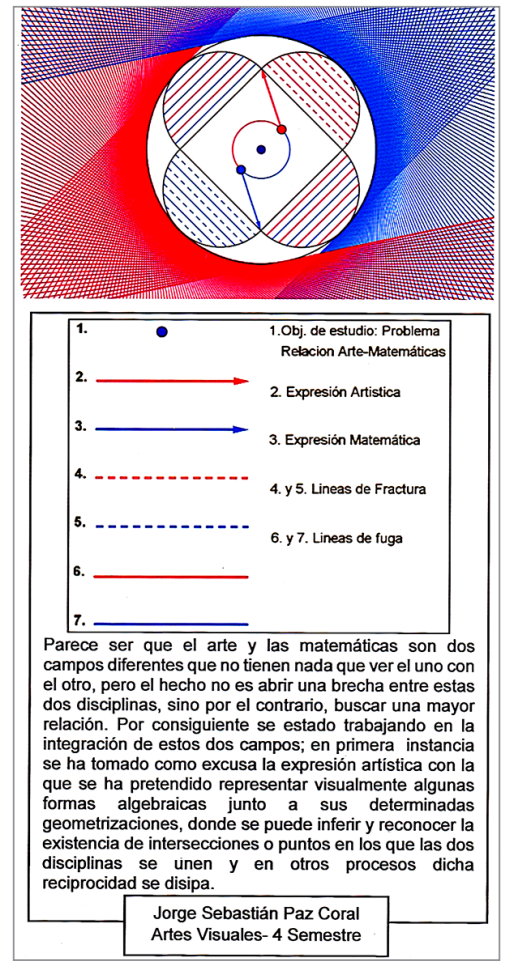

Dispositivo 6. Sebastian Paz. Estudiante V semestre. Artes Visuales. 
En otros dispositivos como es el caso del dispositivo 6, se observan con claridad las líneas de fractura que se representan como un salto entre campos de conocimiento que harán posible profundizar en su búsqueda particular al estudiante que lo creó. Sin duda, todos los dispositivos lograron posicionarse como lugares de enunciación y subjetivación que arrojaban al escenario pedagógico común, es decir al seminario de Arte e Investigación, una parte del mundo de las apreciaciones que en ocasiones el estudiante suele silenciar por temor al rechazo, especialmente cuando hablamos de procesos tan personales como ocurre con la creación artística. El dispositivo, en cierto modo, construía una plataforma, quizás mejor una barca, en la que cada estudiante se sentía confiado y más o menos cómodo para navegar en aguas desconocidas y muy turbulentas. Una barca que se hacía propia, puesto que él mismo la construía a partir de sus capacidades reflexivas y analíticas, pero, más aún, creativas. Los recursos de la imaginación allí fueron indispensables, debido a que logramos entender que entre más se le permitía a la imaginación dar rienda suelta, más aventurados eran los dispositivos, y las creaciones artísticas se potencializaron.

Tal vez sea importante aclarar a los lectores que no se trata de demostrar que nuestro experimento fue exitoso y venderlo como un prospecto de lo que podría ser una metodología para formular un trayecto investigativo basado en la creación, tan solo y como se mencionó al principio, estamos compartiendo una experiencia y ella tiene el sesgo de nuestra propia percepción. En cualquier caso, si el arte es un modo de percepción, también debe serlo la investigación creación, y sin pensarlo la formación en investigación creación, si es que ello puede ser formado. Pienso que este proceso pedagógico en tanto es en sí mismo un acto de creación auténtico producto de la investigación, puedo afirmar que junto a mis estudiantes creamos un proceso artístico e hicimos de este momento, un gesto inaugural $\mathrm{y}$ apasionado desde el punto de vista investigativo, creativo y pedagógico. 


\subsection{Líneas de subjetivación=Líneas fuerza}

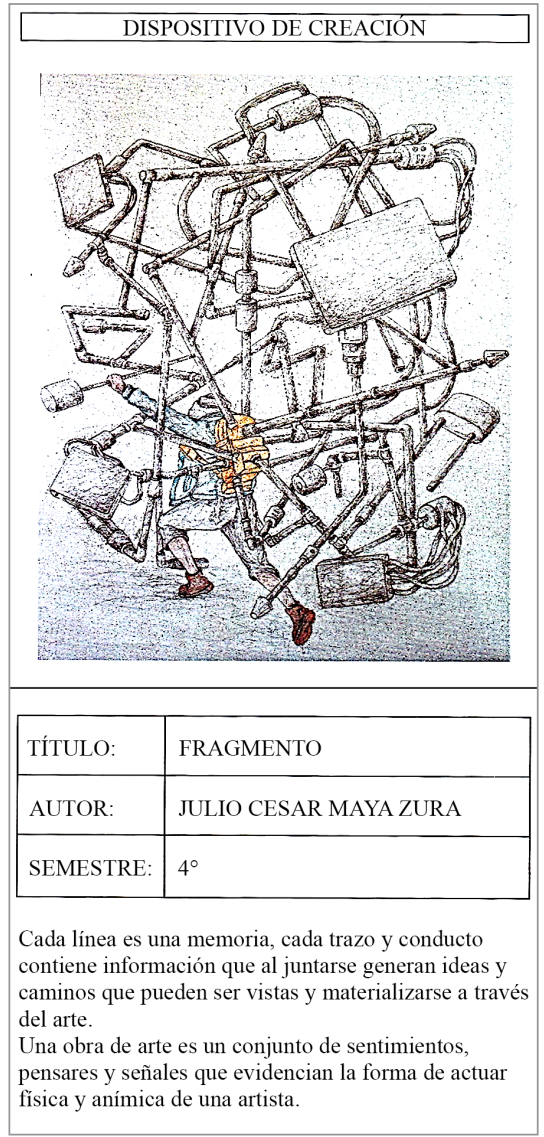

Dispositivo 7. Julio Cesar Maya. Estudiante V semestre. Artes Visuales.

En el seminario de Arte e Investigación, la experiencia artística puede tener diferentes lugares, tiempos, duraciones e importancias. Esto complejiza la categorización, pero permite por otro lado una taxonomía dinámica en la que se pueden hacer preguntas como: ¿En qué momentos, en qué fases y tiempos, se realiza una investigación artística? La primera cuestión que dinamiza estos interrogantes se relaciona con la utilización de diversos métodos a partir de la experimentación, en nuestro caso a partir de la investigación 
basada en la creación; en segundo lugar, aspectos como la motivación, la inspiración, la reflexión, la discusión, la formulación de preguntas de investigación producto de otras concepciones y la implementación y uso de conceptos, componen otro de los aspectos importantes frente a la pregunta por el diseño de metodologías en la investigación creación. En la investigación basada en la creación, tiene sentido preguntarse por: ¿Quiénes somos?, ¿Cómo queremos vivir?, ¿Qué significan las cosas?, ¿Qué podemos saber?, ¿Cuándo existe algo?, ¿Qué es el tiempo?, ¿Dónde está el sentido común?, ¿Podría ser de otra manera? Estos son ejemplos de las preguntas que los estudiantes se hicieron en la creación de sus dispositivos, como vemos en el dispositivo 7. Allí, el propio dispositivo es más que un modelo o diseño metodológico, en él es evidente el acto creativo en el que se conjugan algunas de estas preguntas y se da respuesta en algún sentido a ellas remezclando aspectos físicos y anímicos del artista creador.

A través de este experimento de formación en investigación para artistas creadores, se produjeron conocimientos específicos sobre estas cuestiones que no podrían ser entregados de otra manera. No se dice más aquí que, la investigación basada en los procesos de creación es productora de conocimiento, y que valela pena preguntar por el conocimiento o tipo de conocimiento que ella produce o, mejor aún, cuáles son los dispositivos que pueden provocar la creación o, como afirma Gerard Vilar, filósofo catedrático de la Universidad de Barcelona, el arte más que producir conocimiento, crea dispositivos.

El proceso de subjetivación-objetivación dado en los dispositivos, se entendió como "la reunión de una serie de actos conscientes en el sujeto al respecto de la percepción de las cosas del mundo que recontextualizaron en algún sentido una pregunta esencial, la pregunta por el ser que es quien encarna lo producido por la afectación de la percepción o mirada sobre las cosas del mundo convirtiéndose en un proceso de subjetivación" (Castaño, 2015, p. 9), y, por lo tanto, en tema de interés para el campo de la formación en investigación creación. 


\subsection{Conclusiones preliminares}

Como se trató de un experimento que ha de seguir tomando fuerza en el quehacer pedagógico de la formación en investigación creación, considero que es importante plantear algunas conclusiones preliminares antes del cierre.

En primer lugar, en lo que respecta a la comprensión del fenómeno de producción de subjetividad basada en la experiencia de creación del dispositivo como herramienta de diseño metodológico para un artista creador, vale la pena mantener activa y vigente una pregunta por el ser del que podemos decir que, "es quien dota de sentidos su propia existencia y a las cosas del mundo como afectaciones de ello, anudamientos que entenderemos aquí como función de habitar" (Castaño, 2015, p. 35) la experiencia sensible del mundo y el acontecer cotidiano de la creación. Pienso también en una perspectiva sistémica, autopoética donde no es necesario un ser que habite, sino que el habitar se habita a sí mismo, y en esa fuerza intrínseca interactúa con otras fuerzas que son las que percibimos. Mientras nos identificamos solo con una parte del sistema, sufrimos, pero si nos identificamos con todo, estaremos integrados a una fuerza mayor que reducirá, incluso, desvanecerá completamente la identificación de alguna entidad subjetiva con el dolor.

Una interpretación del sí mismo del ser que se enfrenta de este modo con dificultades que se fundamentan en el objeto temático o de creación y generan un proceso de singularidad de la afectación. A estas singularidades es a las que llamamos procesos de subjetivación. Los procesos de subjetivación que se produjeron fueron pensados como formas de habitar el mundo del ser estético, reconocibles en los textos, las imágenes e incluso en las conversaciones que se generaron en el espacio del seminario de Arte e Investigación.

Además, es altamente significativo tener en cuenta en el futuro inmediato, distintos niveles del ser, del sí mismo, de la singularidad y de los procesos de subjetivación, dado que el "yo" se reconfigura a través del arco de la vida y puede abordarse desde tres perspectivas: 
el "yo-distal", o sea aquel que dice "mío", el "yo-proximal", o sea aquel que se ve como protagonista de la experiencia, y el "yo-anterior" que es naturalmente consciente de los dos anteriores y que no logra verse a sí mismo como un objeto, en otras palabras, un sujeto puro. Estos matices del yo permitirán puntualizar con mayor precisión la relación entre "proceso" y "conciencia del proceso" no solo como conciencia histórica, sino también como conciencia inmediata y las implicaciones de esta última en los proyectos de investigación.

En segundo lugar y sobre la experiencia obtenida en el desarrollo de este experimento pedagógico, que es al mismo tiempo un experimento de creación, no podría finalizar sin resaltar la enorme relación de él con dos de las consecuencias fundamentales que plantea Deleuze al respecto de los dispositivos y que se encuentran presentes en este proceso. Por un lado, la indudable resistencia a los universales, puesto que todas las líneas poseen coordenadas inconstantes y completamente variables; y por otro, lo relacionado con la riqueza de multiplicidades que ofrece el dispositivo. Ambas encajan perfecto con el quehacer del investigador creador y por eso es que los dispositivos, en la mayoría de los casos, resultaron ser una experiencia que permitió contar la originalidad de cada proceso de enunciación creativa de mis estudiantes, pero que al mismo tiempo, a mí como docente y artista, me lo hizo posible. Se trató en todos los casos, es decir, desde la pedagogía, la investigación y la práctica artística de una "creatividad variable" como lo expresaba Deleuze por la novedad y significancia en la experiencia de cada uno de los participantes.

Todo dispositivo se define por su tenor de novedad y creatividad, el cual marca al mismo tiempo su capacidad de transformarse o de fisurarse y en provecho de un dispositivo del futuro. En la medida en que se escapan de las dimensiones de saber y poder, las líneas de subjetivación parecen especialmente capaces de trazar caminos de creación que no cesan de abortar, pero también de ser reanudados, modificados, hasta llegar a la ruptura del antiguo dispositivo (Deleuze, 1990, p. 159). 
Por supuesto, que no estamos dispuestos a cometer los mismos errores de la posmodernidad cuando lleva su valiosa idea de que las "verdades dependen del contexto", al nefasto extremo de que "no hay verdades", lo cual nos tiene hoy atascados en el infernal momento de la "pos-verdad". La resistencia a los universales que planteamos aquí no es un rechazo, sino un escepticismo sano que no desconoce las evidencias de verdades que nos unen independientemente de nuestros contextos, como por ejemplo, la idea misma (evidentemente universal) de que la verdad depende del contexto. Como se puede apreciar, paradójicamente, esta misma verdad no depende del contexto. De igual manera, no promovemos una multiplicidad por la multiplicidad, un mero juego de palabras como si solo se tratara de abalorios, sino que apostamos por la autenticidad, por el territorio que se inscribe en el cuerpo y en la mente.

Finalmente, y como un modo de comprometernos con la trascendencia del pensamiento en el futuro próximo, nos aventuramos a una tarea ineludible en el panorama actual mundial: hacer un ejercicio amoroso de decolonización del pensamiento y poner en diálogo conceptos venidos de occidente, como el de "dispositivo" con conceptos poético-políticos nacidos de nuestras propias huellas ancestrales en américa, como el de "tejido". Sabemos que es un deber contextual aportar al diálogo de las nuevas ancestralidades, y este será sin duda nuestro siguiente paso.

Cierro dando gracias una vez más a mis estudiantes y a la expectativa de lo que será el nuevo viaje.

\section{Referencias}

Arendt, H. (2006). Los orígenes del totalitarismo. Editorial Alianza.

Benjamín, W. (2013). Sobre la fotografía. Pre-textos.

Castaño, E. (2015). Mirar y habitar. Estudio sobre la mirada en las casas abandonadas. [tesis de Maestría en Educación, Universidad Pedagógica Nacional]. Repositorio institucional UPN.

Deleuze, G. et al. (1990). Qué es un dispositivo. En: Michel Foucault filósofo. Editorial Gedisa. 